\title{
KOMPOSISI SPESIES LARVA LOBSTER YANG TERKUMPUL PADA ATRAKTOR LAMPU BAWAH AIR
}

\author{
Arief Setyanto $^{\mathrm{a}, \mathrm{b}} *$, Firda Nikmatul Kamila ${ }^{\mathrm{a}}$, Gatut Bintoro $^{\mathrm{a}}$ \\ ${ }^{a}$ Pemanfaatan Sumberdaya Perikanan, Fakultas Perikanan dan Ilmu Kelautan, Universitas Brawijaya \\ Jl. Veteran, Malang, Indonesia \\ ${ }^{\mathrm{b}}$ Coastal Resilience and Climate Change Adaptation (CORECT) Research Group, Faculty of Fisheries \\ and Marine Science, Universitas Brawijaya, Malang-Indonesia \\ *Koresponden penulis : asetyanto@ub.ac.id
}

\begin{abstract}
Abstrak
Lobster (Panulirus sp.) merupakan hewan avertebrata anggota Filum Arthropoda. Di Indonesia terdapat 6 spesies lobster dari genus Panulirus yaitu $P$. homarus, $P$. longipes, $P$. ornatus, $P$. penicillatus, $P$. polyphagus dan $P$. versicolor. Keenam spesies lobster ini memiliki distribusi yang berbeda-beda. Fase hidup lobster sangat komplek. Fase larva adalah relative lama dan mempunyai beberapa tahap yangmana kelulushidupan dalam fase ini sangat menentukan populasi alaminya. Fase larva lobster termasuk dalam plankton yang makanannya tergantung pada jenis mikroorganisme lainnya. Mikroorganisme umumnya adalah phototaksis positive. Studi tentang pengaruh cahaya terhadap komposisi spesies larva lobster menarik dilakukan karena dapat memberikan informasi bagi upaya budidaya dan peningkatan jumlah populasi melalui penurunan kematian alaminya. Penelitian ini di laksanakan di perairan Pantai Lampon, Banyuwangi, Jawa Timur tahun 2019. Pada penelitian ini analisis yang digunakan adalah analisis Chi-Square, uji $F$ (ANOVA), dan uji lanjutan. Hasil dari penelitian ini adalah spesies larva lobster yang terkumpul pada atraktor lampu dan tanpa atraktor ada empat speseis yaitu P. ornatus, P. homarus, P. penicillatus, dan P. versicolor. Spesies yang dominan terkumpul adalah P. homarus. Pada penelitian ini penggunaan atraktor lampu celup bawah air lebih berpengaruh terhadap jumlah larva lobster untuk mendekat kearah atraktor. Keberhasilan pengelolaan sumberdaya perikanan lobster akan sangat ditentukan oleh hasil kajian yang mencakup seluruh siklus hidupnya.
\end{abstract}

Kata kunci : Cahaya, chi-square, distribusi, kelulushidupan, komplek.

\begin{abstract}
Lobster (Panulirus sp.) is an invertebrate animal belonging to the phylum Arthropoda. In Indonesia there are 6 species of lobster from the genus Panulirus, namely $P$. homarus, $P$. longipes, $P$. ornatus, $P$. penicillatus, $P$. polyphagus and $P$. versicolor. These six lobster species have different distribution. The life phase of lobster is very complex. The larval phase is relatively long and has several stages in which survival in this phase largely determines its natural population. Lobster larval phase is included in plankton whose food depends on other types of microorganisms. Microorganisms generally are positive phototaxis. The study of the effect of light on the composition of lobster larva species is interesting because it can provide information for cultivation efforts and increase population through decreasing natural mortality. This research was carried out in the waters of Lampon Beach, Banyuwangi, East Java in 2019. In this study the analysis used was the Chi-Square analysis, F test (ANOVA), and further tests. The results of this study are lobster larvae collected in lamp attractors and without attractors there are four species, namely P. ornatus, P. homarus, P. penicillatus, and P. versicolor. The dominant species collected is P. homarus. In this study the use of underwater lamp attractors has more influence on the number of lobster larvae to get closer to the attractor. Successful management of lobster fishery resources will be largely determined by the results of studies that cover the entire life cycle.
\end{abstract}

Keywords : Light, chi-square, distribution, survival, complex.

\section{PENDAHULUAN}

Biogeografi Laut Selatan Jawa adalah masuk dalam klasifikasi diantara 232 eco- regions yang diusulkan pada system global untuk area pesisir dan paparan yang dikenal sebagai Eko-region Laut Dunia (Marine Eco- 
regions of the World/MEOW). Eko-region Laut Selatan Jawa adalah masuk dalam kelompok the Central Indo-Pacific marine realm and Java Transitional provinces [1]. Wilayah transisi Jawa meliputi wilayah the South Java Sea, South Nusa Tenggara Sea, Sawu Sea, and West of Timor Sea.Panjang pantai laut Selatan Jawa adalah sekitar $1,500.12 \mathrm{~km}$ yang terbentang dari semenanjung Ujung Kulan (Pandeglang, Banten Province) di sebelah Barat sampai dengan semenanjung Blambangan (Banyuwangi, East Java Province) di sebelah Timur. Perikanan lobster di Selatan Jawa didominasi oleh perikanan nelayan skala kecil. Dan mereka umumnya adalah dikelompokkan sebagai jenis perikanan yang multi-gear dan multi-spesies. Hal itu dikarenakan nelayan lobster juga menangkap jenis perikanan lain seperti: bawal, tongkol, gurita dengan alat tangkap yang berbeda antara satu target penangkapan dengan target yang lain.

Meskipun didominasi oleh perikanan skala kecil, namun kontribusi terhadap produksi perikanan nasional adalah sangat besar. Walaupun secara kuntitas (volume) produksi nasional lobster sangat rendah, namun secara kualitas (rupiah) sangat tinggi bahkan tertinggi kedua dibandingkan komoditi perikanan yang lain. Hal ini dikarenakan lobster adalah produk perikanan untuk ekspor.Lobster dari family Palinuridae mendiami seluruh perairan laut tropis dan sub-tropis dimana lobster menjadi sangat penting secara ekologi dan ekonomi.

Kebanyakan spesies ikan dan dekapoda pesisir mempunyai fase larva yang pelagis dan menyebar yang kemudian berakhir dengan settlement pada habitat pesisir yang sesuai.Studi terkini menunjukkan bahwa larva secara aktif mencari habitat yang sesuai tersebut dengan menggunakan kemampuan renang dan sensor [2]. Daur hidup lobster ini mencakup transisi dari fase larva yang planktonic (phyllosome) yang kemudian bermetamorfosis ke tahap berikutnya menjadi fase post-larvae yang bersifat nekton (puerulus) yang bergerak ke arah pantai untuk menetap pada perairan pantai yang dangkal. Yang kemudian akan mengalami molting untuk menjadi lobster kecil yang bersifat bentik dan menetap [3].

Fase larva lobster adalah relative sangat lama yaitu sampai hampir 18 bulan pada beberapa spesies yang biasanya meliputi 7-13 tahap fase phyllosome yang berbeda dengan masing-masing tahap ditandai dengan satu atau lebih masa kepompong (instar) [4].Pada fase awal tahap pertumbuhan phyllosome yang dialami setelah menetas dari telur adalah mempunyai kemampuan berenang yang sangat terbatas.Hal itu mengakibatkan mereka tersebar luas ke perairan lepas pantai oleh gelombang.Sehingga pada tahap akhir fase phyllosoma pada kebanyakan spesies palinurid sering ditemukan di perairan samudera (oceanic) di luar batas continental sejauh kurang lebih $1500 \mathrm{~km}$ dari pantai [57].

Lokasi dan pemicu metamorphosis dari tahap akhir fase phyllosoma ke fase puerulus adalah belum pasti karena kesulitan dalam mendapatkan hasil bukti suatu observasi atau eksperimen.Pada saat masa akhir fase phyllosoma telah bermetamorfosis menjadi puerulus, mekanisme dimana mereka bergerak ke arah pantai ke dalam perairan dangkal untuk tinggal adalah juga belum jelas. Akan tetapi kemungkinan hal itu melibatkan suatu kombinasi antara kemampuan berenang secara aktif ke arah pantai dan penggunaan proses alami yang ada di pantai atau proses pasif seperti arus permukaan yang ditimbulkan oleh angin [8].

Meskipun pada satu sisi sebenarnya bukti pergerakan aktif menuju ke pantai adalah sangat lemah karena bukti diperoleh dari pengukuran daya renang yang sangat pendek dan konsumsi energy yang dikeluarkan juga sangat kecil [9].Kemudian pada sisi yang lain bukti adanya pergerakan pasif ke arah pantai diperoleh dari hubungan korelasi antara waktu saat puerulus yang menetap/settle dengan fenomena alam seperti angin pantai, hujan, dan pola arus [10-12].

Distribusi puerulus pada beberapa survey lepas pantai mengindikasikan bahwa pergerakan mereka adalah menuju ke arah pantai dibandingkan dengan pergerakan yang menyebar secara acak.Pernyataan ini 
menyimpulkan bahwa fase puerulus dan fase akhir phyllosoma adalah mampu bergerak ke arah pantai atau perairan lebih dangkal dari perairan lepas pantai yang berjarak lebih dari $50 \mathrm{~km}$. pergerakan ini adalah masa dimana terjadi proses settlement. Masa ini sangat berpengaruh terhadap stok populasi lobster local yang secara tidak langsung berpengaruh terhadap hasil tangkap lobster setempat [13].

Dari penjelasan di atas disimpulkan bahwa perikanan lobster sangat penting bagi ekonomi Indonesia. Akan tetapi tindakan menejemen perikanan lobster untuk melindungi dan menjaga kelestarian sumberdaya lobster relatif terabaikan. Sehingga tujuan dari pada kegiatan ini adalah untk mengembangkan formulasi untuk melindungi ekosistem dan melestarikan sumberdaya lobster. Hal pertama yang perlu dilakukan mempelajari pola penyebaran larva lobster tiap spesies secara spasial dan temporal.

\section{METODE}

\section{Waktu dan Tempat Penelitian}

Lokasi sampling adalah Pantai Selatan Pulau Jawa bagian propinsi Jawa Timur tepatnya di perairan pantai Lampon, Banyuwangi. Waktu sampling dilakukan dalam bulan Juli-Agustus 2019.

\section{Metode Pengumpulan Data}

Data yang dikumpulkan merupakan hasil tangkapan larva lobster nelayan. Alat pengumpul larva dioperasikan dengan perlakuan lampu bawah air. Tiap spesies larva yang ditemui diambil sampel untuk diidentifikasi langsung di lokasi sampling. Sampel kemudian dihitung jumlah per individu per spesies pada tiap perlakuan. Dokumentasi perwakilan spesies dilakukan di lokasi yang kemudian diulang lagi saat sampel diidentifikasi secara detail di laboratorium.

\section{Analisis Data}

Data dari setiap benih lobster hasil pengumpulan akan dilihat ciri fisiknya. Ciri fisik ini akan dijadikan sebagai acuan dalam menentukan jenis spesies pada masingmasing individu lobster. Pada tahap ini identifikasi lobster disesuaikan dengan kebiasaan dan keahlian yang dimiliki oleh nelayan. Data ini akan dicatat, difoto dan kemudian akan dicocokkan dengan buku kunci identifikasi "Identification of tropical palinurid lobster puerulus and juveniles" oleh Clive Jones (unpublished, 2010). Analisa statistik dilakukan dengan metode chi square dan uji F (ANOVA/Analysis of Variance).

\section{HASIL DAN PEMBAHASAN}

\section{Spesies Benih Lobster Yang Terkumpul Atraktor}

Spesies benur lobster yang terkumpul pada atraktor di Pantai Lampon yaitu empat jenis spesies diantaranya Lobster Mutiara (Panulirus ornatus), Pasir (Panulirus homarus), Batu (Panulirus penicillatus), dan Bambu (Panulirus versicolor). Masingmasing spesies memiliki penciri yang berbeda, hasil dapat dilihat pada Tabel 1 .

Tabel 1 Identifikasi benih lobster

\begin{tabular}{|c|c|c|c|}
\hline No & Nama & Spesies & Ciri-ciri \\
\hline 1 & Mutiara & $\frac{\text { Panulirus }}{\text { ornatus }}$ & $\begin{array}{l}\text { Penciri dari larva } \\
\text { lobster Mutiara } \\
\text { (Panulirus ornatus) } \\
\text { dilihat dari antenanya } \\
\text { setiap larva lobster } \\
\text { jika di bandingkan } \\
\text { dengan tubuhnya } \\
\text { akan mengalami } \\
\text { kesulitan, jadi untuk } \\
\text { membedakan hanya } \\
\text { cukup dengan melihat } \\
\text { perbedaan dari } \\
\text { antena. Lobster } \\
\text { Mutiara memiliki ciri } \\
\text { diantenanya yaitu } \\
\text { terdapat cincin hitam } \\
\text { kemudian bagian } \\
\text { ujung antenna } \\
\text { terdapat benjolan } \\
\text { kecil dan ini dapat } \\
\text { menyala ketika di } \\
\text { masukan kedalam } \\
\text { ember berwarna } \\
\text { hitam. }\end{array}$ \\
\hline 2 & Pasir & $\underline{\text { Panulirus }}$ & $\begin{array}{l}\text { Lobster Pasir } \\
\text { (Panulirus homarus) } \\
\text { memiliki penciri yang } \\
\text { hampir mirip dengan } \\
\text { lobster Mutiara tetapi } \\
\text { pembedanya lobster } \\
\text { pasir yaitu tidak }\end{array}$ \\
\hline
\end{tabular}




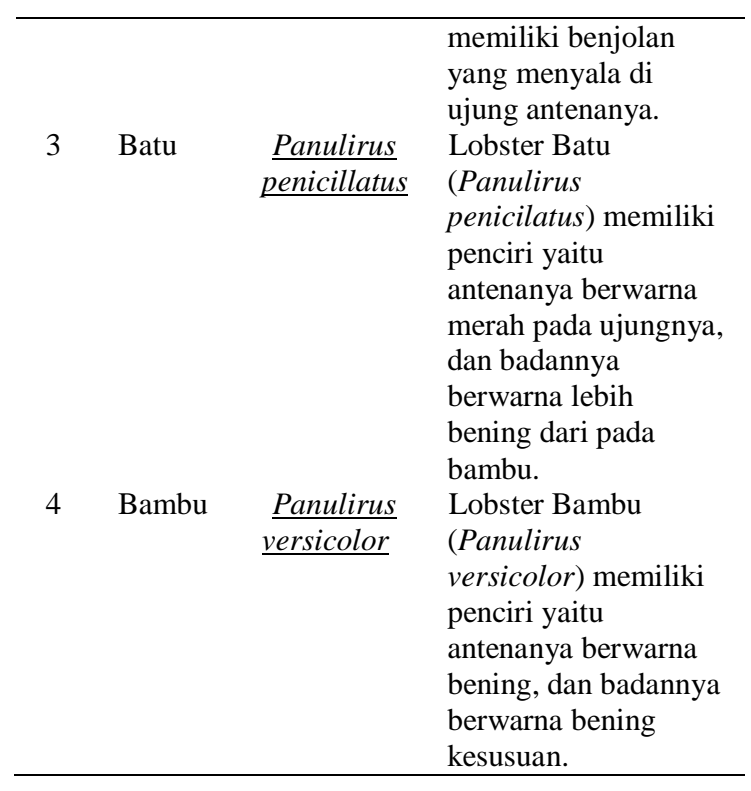

\section{Komposisi Spesies Benih Lobster}

Hasil dari penelitian ini diperoleh hasil persebaran spesies puerulus lobster pada penggunaan lacuba yang berbeda. Pada tanggal 27 Februari-31 Maret 2019, dengan 20 kali pengulangan, selama penelitian didapatkan hasil seperti pada Tabel 2 .

Tabel 2. Komposisi puerulus lobster

\begin{tabular}{lccccc}
\hline \multirow{2}{*}{ PERLAKUAN } & \multicolumn{2}{l}{ Spesies Puerulus Lobster } & Total \\
\hline & L. & L. & L. & L. & \\
& MUTIARA & PASIR & BATU & BAMBU & \\
\hline LACUBA & 91 & 1142 & 214 & 132 & 1579 \\
NO LACUBA & 58 & 1030 & 159 & 99 & 1346 \\
Total & 149 & 2172 & 373 & 231 & 2925 \\
\hline
\end{tabular}

Presentase hasil puerulus lobster yang terkumpul pada atraktor tertiggi pada penggunaan lacuba yang berbeda adalah Lobster Pasir ( $P$. homarus). Puerulus yang memiliki nilai Presentase paling rendah pada penggunaan lacuba yang berbeda adalah Lobster Mutiara ( $P$. ornatus), hasil ini dapat dilihat pada Gambar 1.



Gambar 1. Grafik komposisi spesies benur pada perlakuan lacuba dan tanpa lacuba.

\section{Analisis Komposisi Spesies Puerulus}

Analisis komposisi spesies puerulus Lobster bertujuan untuk mengetahui dan membuktikan secara statistik bahwa komposisi lobster pada penggunaan alat bantu lacuba yang berbeda adalah berbeda atau tidak berbeda maka akan dilakukan uji statiistik menggunakan analisis Chi-square. Adapun hasil Chi-square dapat dilihat pada tabel 3.

Tabel 3. Perhitungan Chi-Square

\begin{tabular}{lrrrr}
\hline \multicolumn{1}{c}{ Spesies } & \multicolumn{2}{c}{ Menggunakan Lacuba } & \multicolumn{2}{c}{ Tidak Menggunakan Lacuba } \\
\hline & Observed & Expected & Observed & Expected \\
\hline L. Mutiara & 91 & 80.43 & 58 & 68.57 \\
L. Pasir & 1142 & 1172.51 & 1030 & 999.49 \\
L. Batu & 214 & 201.36 & 159 & 171.64 \\
L. Bambu & 132 & 124.70 & 99 & 106.30 \\
\hline \multicolumn{5}{c}{ Chi-square $=7,39 . \mathrm{df}=3, \mathrm{p}<0,05$} \\
\hline
\end{tabular}

Pada hasil perhitungan Chi-square menunjukkan nilai 7,39 sedangkan Chisquare table $\mathrm{p}=0,05, \mathrm{df}=3$ adalah 7,815 . Sehingga kesimpulannya terima H0 karena $\mathrm{X} 2$ hitung $\leq \mathrm{X} 2$ tabel, maka terima $\mathrm{H} 0$ atau tolak H1. Yakni hipotesis H0: Setiap menggunakan dan tanpa menggunakan alat bantu lampu celup bawah air memiliki komposisi spesies lobster yang sama.

\section{Komposisi Spesies Benih Lobster Menggunakan Lampu Celup Bawah Air}

Terbukti bahwa komposisi puerulus lobster pada penggunaan alat bantu lacuba sama, maka selanjutnya akan dilakukan uji ANOVA. Uji Analisis Of Varian (ANOVA) digunakan untuk mengetahui perbedaan setiap perlakuan yang digunakan pada penelitian ini.Adapun hasil perhitungan ANOVA untuk komposisi spesies benih 
lobster menggunakan lampu celup bawah air, hasil dapat dilihat pada tabel 4

Tabel 4. ANOVA menggunakan lacuba

ANOVA

\begin{tabular}{llllll}
\hline & $\begin{array}{l}\text { Sum of } \\
\text { Squares }\end{array}$ & df & $\begin{array}{l}\text { Mean } \\
\text { Square }\end{array}$ & F & Sig. \\
Between Groups & 9.475 & 3 & 3.158 & 107.750 & .000 \\
Within Groups & 1.759 & 60 & .029 & & \\
Total & 11.233 & 63 & & & \\
\hline
\end{tabular}

Hasil uji ANOVA untuk nilai Between groups adalah 9,475 dengan nilai degree of freedom (df) sebesar 3, sedang nilai Within groups adalah 1,759 dengan nilai degree of freedom (df) sebesar 60. Nilai signifikasi yang diperoleh adalah 0,000 , hal ini dapat dilihat pada tabel 10. Hal ini berarti nilai tersebut lebih kecil dari 0,05 maka terima $\mathrm{H} 1$ tolak $\mathrm{H} 0$ yakni hipotesis

H1 : Ada perbedaan yang signifikan terhadap benih lobster yang terkumpul pada atraktor dengan menggunakan alat bantu lampu celup bawah air.

Perlu dilakukan uji lanjutan (Tukey) untuk mengetahui spesies mana yang memiliki beda yang sangat nyata. Hasil uji lanjutan antar spesies dapat dilihat pada tabel 5 .

Tabel 5. Hasil notasi tukey

\begin{tabular}{lcccc}
\hline Spesies & $\mathrm{N}$ & 1 & 2 & 3 \\
\hline Mutiara & 14 & .7620 & & \\
Bambu & 12 & & 1.0041 & \\
Batu & 18 & & 1.0497 & \\
Pasir & 20 & & & 1.7442 \\
Sig. & & 1.000 & .881 & 1.000 \\
\hline
\end{tabular}

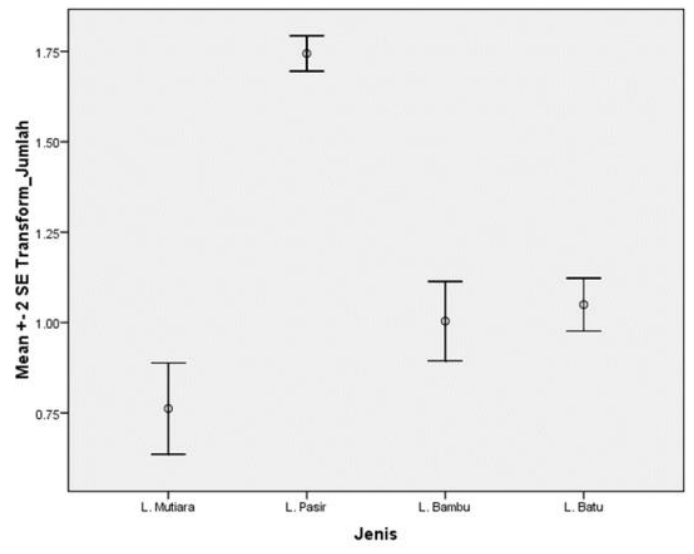

Gambar 2. Grafik subset menggunakan lacuba.

Hasil uji lanjutan pada tabel 5 dapat diketahui adanya perbedaan nyata antar spesies puerulus lobster yang terkumpul pada atraktor. Perbedaan notasi antar spesies menunjukkan bahwa spesies tersebut memiliki beda yang sangat nyata dengan yang lainnya. Spesies Lobster Pasir ( $P$. homarus) memiliki perbedaan sangat nyata dengan spesies Lobster Mutiara (P. ornatur), Lobster Bambu ( $P$. versicolor) dan Lobster Batu ( $P$. penicillatus). Kemudian untuk Lobster Bambu (P. versicolor) dan Lobster Batu ( $P$. penicillatus) memiliki perbedaan nyata terhadap Lobster Pasir ( $P$. homarus) dan Lobster Mutiara $(P$. ornatus).Lobster Mutiara $(P$. ornatus)memiliki perbedaan sangat nyata dengan spesies Lobster Pasir ( $P$. homarus), Lobster Bambu ( $P$. versicolor) dan Lobster Batu ( $P$. penicillatus). Hal ini juga dapat dilihat pada subset yang ada pada Gambar 2. Bahwasanya subset yang tidak ada pada satu garis yang sama maka menunjukkan bahwa memiliki perbedaan yang nyata.

\section{Komposisi Spesies Benih Lobster Tidak Menggunakan Lampu Celup Bawah Air}

Hasil uji ANOVA untuk nilai Between groups adalah 10,802 dengan nilai degree of freedom (df) sebesar 3, sedang nilai Within groups adalah 2,976 dengan nilai degree of freedom (df) sebesar 56. Nilai signifikasi yang diperoleh adalah 0,000 Tabel 6 . ANOVA tidak menggunakan lacuba. Hal ini berarti nilai tersebut lebih kecil dari 0,05 maka maka terima H1 tolak H0 yakni hipotesis H1 : Ada perbedaan yang signifikan terhadap benih lobster yang terkumpul pada atraktor dengan tidak menggunakan alat bantu lampu celup bawah air.

Tabel 6. ANOVA tidak menggunakan lacuba

\begin{tabular}{|c|c|c|c|c|c|}
\hline \multicolumn{6}{|c|}{ ANOVA } \\
\hline & $\begin{array}{l}\text { Sum of } \\
\text { Squares }\end{array}$ & $\mathrm{df}$ & $\begin{array}{l}\text { Mean } \\
\text { Square }\end{array}$ & $\mathrm{F}$ & Sig. \\
\hline Between Groups & 10.802 & 3 & 3.601 & 67.755 & .000 \\
\hline Within Groups & 2.976 & 56 & .053 & & \\
\hline Total & 13.778 & 59 & & & \\
\hline
\end{tabular}

Perlu dilakukan uji lanjutan (Tukey) untuk mengetahui spesies mana yang memiliki beda yang sangat nyata. Hasil uji lanjutan antar spesies dapat dilihat pada tabel 7. 
Tabel 7. Hasil notasi tukey

\begin{tabular}{lllll}
\hline Spesies & $\mathrm{N}$ & 1 & 2 & 3 \\
\hline Mutiara & 11 & .6568 & & \\
Batu & 18 & .8667 & .8667 & \\
Bambu & 11 & & .8995 & \\
Pasir & 20 & & & 1.7012 \\
Sig. & & .089 & .982 & 1.000 \\
\hline
\end{tabular}

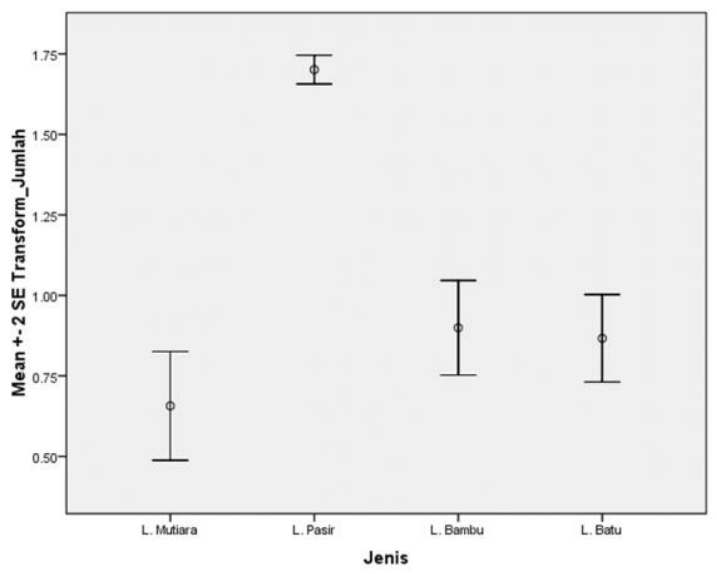

Gambar 3. Grafik subset tidak menggunakan lacuba.

Hasil uji lanjutan pada Tabel 7 dapat diketahui adanya perbedaan nyata antar spesies puerulus lobster yang terkumpul pada atraktor. Perbedaan notasi antar spesies menunjukkan bahwa spesies tersebut memiliki beda yang sangat nyata dengan yang lainnya. Spesies Lobster Pasir ( $P$. homarus) memiliki perbedaan sangat nyata dengan spesies Lobster Mutiara ( $P$. ornatur), Lobster Bambu ( $P$. versicolor) dan Lobster Batu ( $P$. penicillatus). Kemudian untuk Lobster Bambu (P. versicolor) dan Lobster Batu ( $P$. penicillatus) memiliki perbedaan nyata terhadap Lobster Pasir ( $P$. homarus) dan Lobster Mutiara ( $P$. ornatus). Lobster Mutiara ( $P$. ornatus) dan Lobster Batu $(P$. penicillatus ) memiliki perbedaan nyata dengan spesies Lobster Pasir ( $P$. homarus) dan Lobster Bambu (P. versicolor). Hal ini juga dapat dilihat pada subset yang ada pada Gambar 3. Bahwasanya subset yang tidak ada pada satu garis yang sama maka menunjukkan bahwa memiliki perbedaan yang nyata. Perlakuan lampu atau cahaya pada study ini menemukan bahwa komposisi spesies larva (puerullus) tidak berbeda. Pada perlakuan lampu bawah air jumlah individu puerulus lebih banyak ditemukan. Spesies dominan pada kedua perlakuan adalah jenis lobster pasir (P. homarus). Hal ini sinkron dengan dominasi jenis pasir yang ditemukan di laut Selatan Pulau Jawa [14].

Penyebaran atau pergerakan puerulus [15] [16]di periran banyak dipengaruhi oleh factor kimia dan fisika selain biologi $[2,17$, 18]. Crustacea merupakan jenis zooplankton yang terpenting bagi ikan-ikan baik di perairan tawar maupun perairan laut. Pada phylum Arthropoda, hanya crustacea yang dapat hidup sebagai plankton dalam perairan. Zooplankton banyak terdapat di perairan pantai terutama dekat dengan muara sungai karena pada muara sungai banyak terdapat makanan zooplankton yaitu fitoplankton dan terdapat banyak zat hara yang terbawa oleh arus. Distribusi atau pergerakan puerullus mungkin sangat dipengaruhi oleh keberaddan makanan yang melimpah di dekat pantai atau perairan dangkal [19].

\section{KESIMPULAN}

1. Terdapat empat jenis spesies selama 20 kali pengulangan dengan perlakuan penggunaan alat bantu lacuba yang berbeda diantaranya Lobster Mutiara (Panulirus ornatus), Lobster Pasir (Panulirus homarus), Lobster Batu (Panulirus penicillatus), dan Lobster Bambu (Panulirus versicolor). Setiap benih lobster memiliki penciri yang berbeda dan bisa dibedakan dengan kasat mata. Puerulus yang terkumpul pada atraktor didominasi oleh Lobster Pasir (Panulirus homarus) baik menggunakan lacuba ataupun tidak.

2. Penggunaan alat bantu lampu celup bawah air mempengaruhi banyaknya komposisi spesies puerulus lobster. Dengan menggunakan alat bantu lampu celup bawah air menarik puerulus lobster untuk mendekat ke arah atraktor, karena pada sumber cahaya banyak makanan yang terkumpul dan puerulus lobster bisa berlindung di sela-sela atraktor.

\section{SARAN}

Perlu adanya penelitian lanjutan mengenai makanan puerulus lobster di Selatan Banyuwangi, Jawa Timur. Penggunaan bahan atraktor sebagai 
pengumpul puerulus, perlu diteliti lanjutan kenapa hanya fase puerulus yang terkumpul. Perlunya penelitian lanjutan mengenai daerah pemasangan atraktor yang baik dari segi substrat, jarak dari bibir pantai dan faktor oseanografi yang mempengaruhi.

\section{UCAPAN TERIMA KASIH}

Terima kasih penulis sampaikan kepada para reviewer. Penelitian ini merupakan bagian penelitian yang didukung oleh Direktorat Jenderal Pendidikan Tinggi RI. Terima kasih penulis juga sampaikan kepada Fakultas Perikanan dan Ilmu Kelautan Universitas Brawijaya, Malang, Indonesia.

\section{DAFTAR PUSTAKA}

[1] M. D. Spalding, H. E. Fox, B. S. Halpern, M. A. McManus, J. Molnar, G. R. Allen, et al., "Marine ecoregions of the world: A bioregionalization of coastal and shelf areas," Bioscience, vol. 57, pp. 573-583, Jul-Aug 2007.

[2] M. J. Kingsford, J. M. Leis, A. Shanks, K. C. Lindeman, S. G. Morgan, and J. Pineda, "Sensory environments, larval abilities and local self-recruitment," Bulletin of Marine Science, vol. 70, pp. 309-340, Jan 2002.

[3] W. F. Herrnkind and M. J. Butler, "Settlement Of Spiny Lobster, Panulirus-Argus (Latreille, 1804) In Florida - Pattern Without Predictability," Crustaceana, vol. 67, pp. 46-64, Jul 1994.

[4] B. Phillips and A. Sastry, "Larval ecology," The biology and management of lobsters, vol. 2, pp. 1157, 1980.

[5] R. G. Chittleborough, "Home Range, Homing And Dominance In Juvenile Western Rock Lobsters," Australian Journal of Marine and Freshwater Research, vol. 25, pp. 227-234, 1974.

[6] N. M. Ehrhardt and M. D. Fitchett, "Dependence of recruitment on parent stock of the spiny lobster, Panulirus argus, in Florida," Fisheries Oceanography, vol. 19, pp. 434-447, 2010.

[7] B. F. Phillips, P. A. Brown, D. W. Rimmer, and D. D. Reid, "Distribution And Dispersal of The Phyllosoma Larvae Of The Western Rock Lobster, Panulirus-Cygnus, In The Southeastern Indian-Ocean," Australian Journal of Marine and Freshwater Research, vol. 30, pp. 773-783, 19791979.

[8] M. J. Butler, C. B. Paris, J. S. Goldstein, H. Matsuda, and R. K. Cowen, "Behavior constrains the dispersal of long-lived spiny lobster larvae," Marine Ecology Progress Series, vol. 422, pp. 223-237, 2011.

[9] A. G. Jeffs, J. C. Montgomery, and C. T. Tindle, "How do spiny lobster postlarvae find the coast?," New Zealand Journal of Marine and Freshwater Research, vol. 39, pp. 605-617, 2005.

[10] N. Caputi, "Impact of the Leeuwin Current on the spatial distribution of the puerulus settlement of the western rock lobster (Panulirus cygnus) and implications for the fishery of Western Australia," Fisheries Oceanography, vol. 17, pp. 147-152, 2008.

[11] T. Yoshimura, K. Morinaga, S. Oshimo, Y. Konishi, and T. Goto, "Distribution and dispersal of the early larval stages of the Japanese spiny lobster Panulirus japonicus in the East China Sea," New Zealand Journal of Marine and Freshwater Research, vol. 43, pp. 591-604, Mar 2009.

[12] D. B. Eggleston and R. N. Lipcius, "Shelter Selection By Spiny Lobster Under Variable Predation Risk, Social Conditions, And Shelter Size," Ecology, vol. 73, pp. 992-1011, Jun 1992.

[13] L. D. Arteaga-Ríos, J. Carrillo-Laguna, J. Belmar-Pérez, and S. A. Guzman del 
Proo, "Post-larval settlement of California spiny lobster Panulirus interruptus in Bahía Tortugas, Baja California and its relationship to the commercial catch," Fisheries Research, vol. 88, pp. 51-55, 2007/12/01/ 2007.

[14] A. Setyanto, Soemarno, D. G. R. Wiadnya, and C. Nugroho, "Biodiversity of Lobster (Panulirus) from Eastern Indian Ocean of Indonesia Waters," IOP Conference Series: Materials Science and Engineering, vol. 546, p. 022024, 2019/06/27 2019.

[15] B. Morse, B. Quinn, M. Comeau, and R. Rochette, "Stock structure and connectivity of the American lobster Homarus americanus in the southern Gulf of St. Lawrence: do benthic movements matter?," Canadian Journal of Fisheries and Aquatic Sciences, vol. 75, 03/05 2018.

[16] E. Conklin, A. Neuheimer, and R. Toonen, "Modeled larval connectivity of a multi-species reef fish and invertebrate assemblage off the coast of Moloka'i, Hawai'i," PeerJ, vol. 6, 09/28 2018 .

[17] I. A. Hinojosa, B. S. Green, C. Gardner, J. Hesse, J. A. Stanley, and A. G. Jeffs, "Reef Sound as an Orientation Cue for Shoreward Migration by Pueruli of the Rock Lobster, Jasus edwardsii," PLoS One, vol. 11, Jun 2016

[18] I. Segura-Garcia, L. Garavelli, M. Tringali, T. Matthews, L. Cherubin, J. Hunt, et al., "Reconstruction of larval origins based on genetic relatedness and biophysical modeling," Scientific Reports, vol. 9, 12/01 2019.

[19] M. I. Saunders, P. A. Thompson, A. G. Jeffs, C. Säwström, N. Sachlikidis, L. E. Beckley, et al., "Fussy Feeders: Phyllosoma Larvae of the Western Rocklobster (Panulirus cygnus)
Demonstrate Prey Preference," PLoS One, vol. 7, May 2012 